\title{
REMENCES REDIMITS. \\ EL DOMINI DE L'ALMOINA DEL PA DE LA SEU DE GIRONA $(1331-1458)^{1}$
}

\author{
ROSA LLUCH I BRAMON \\ Institut de Llengua i Cultura Catalanes \\ Universitat de Girona
}

\begin{abstract}
SUMARI
Introducció.- I. El nombre de redempcions. 1. Les persones redimides. 2. Cronologia de les redempcions.- II. Els preus de les redempcions: 1. Els preus als Costums de Girona. 2. Els preus de les redempcions de l'Almoina de Girona. 3. L'evolució dels preus de les redempcions de l'Almoina de Girona.- III. Causes i motius de les redempcions: 1. Matrimoni. 2. Trasllat a un altre mas sense matrimoni. 3. Viduitat i renúncia en favor de parents. 4. Renúncia en favor de l'Almoina i gent que no viu en el mas d'origen. 5. Entrada a l'Església.- Conclusions.
\end{abstract}

\section{INTRODUCCIÓ}

Aquest estudi es proposa una aproximació a la situació de la pagesia de remença de la diòcesi de Girona durant la Baixa Edat Mitjana. Els pagesos de remença es caracteritzaven, com és sabut, pel seu asserviment $\mathrm{i}$ per la seva dependència d'un senyor, fet que els comportava, entre d'altres, l'obligació de pagar un rescat o redempció per tal de deslliurar-se'n i obtenir

\footnotetext{
'Aquest estudi ha estat possible gràcies a una beca FPI dins el projecte finançat per la DGICYT PB94-0507. Agraeixo al Dr. Lluís To les moltes i profitoses indicacions que $m$ 'ha fet durant l'elaboració d'aquest treball.

"Anuario de Estudios Medievales". 27 (1997)
} 
així la possibilitat d'abandonar el domini on vivien. Aquesta redempció, tan característica, és el que dóna el nom de remences als pagesos que estaven sotmesos al vincle servil a Catalunya ${ }^{2}$.

La historiografia ha atribuït al pagament d'aquest rescat un paper central en l'evolució social de la pagesia catalana després de la Pesta Negra perquè els senyors per tal de mantenir les seves terres treballades $i$ afocades van augmentar les quantitats exigides en concepte de redempció o reduiren el nombre de redempcions concedides. En definitiva, sembla que la condició remença empitjorà després de 1348 i així s'assentaren les bases del gran conflicte remença.

En paraules de J. M. Salrach: "Per retenir els pagesos a la terra [després de la Pesta Negra], els feudals estengueren la servitud de la gleva i incrementaren les quantitats exigides en concepte de redempció" ${ }^{3}$. En aquest mateix sentit, Freedman parla d'una “... relativa escassetat de redempcions després del 1348 ...": "Sembla -escriu- que l'epidèmia empitjorà les pràctiques ja odiades, com la redempció"; i també afirma que “... a Catalunya ... la pesta fou seguida per un enduriment del control

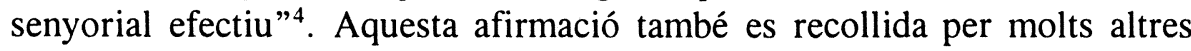
autors; per exemple, A. Riera: "[A les dècades centrals del segle XIV], els grans propietaris a fi de tallar l'emigració en els seus respectius dominis, estenen el servatge $\mathrm{i}$ eleven les quantitats exigides en concepte de re-

\footnotetext{
${ }^{2}$ Entre la ingent bibliografia dedicada al tema dels remences podem destacar Eduardo de HiNOJOSA, Origen y vicisitudes de la pagesia de remensa en Cataluña i El régimen señorial y la cuestión agraria en Cataluña durante la Edad Media, in Obras, vol. II, Madrid, 1955, pp. 9-31 i pp. 33-323, respectivament: Wladimiro PISKORSKI, El problena de la significación y origen de los seis "malos usos" en Cataluña, Barcelona, 1929; Oriol ANGUERA DE SOJo 1 DODERO, Dret especial de la Comarca de Vic, "Conferències sobre varietats comarcals del Dret Civil Català", Barcelona, 1934, pp. 273-340; Jaume VICENS VIVES, El Gran Sindicato Remensa (1488-1508), Madrid, 1954 i Historia de los remensas (en el siglo XV). Barcelona, 1978. Miquel GOLOBARDES, Els remences dins el quadre de la pagesia catalana fins el segle XV, Peralada, 1973, 2 vols.; Josep Maria SALRACH, La Pesta Negra i els origens del problema remença, in "Pere el Cerimoniós i la seva època", CSIC, 1989, pp. 13-34; Paul H. FrEEDMAN Els origens de la servitud pagesa a la Catalunya Medieval, Vic, 1993; Antonio JORDÁ FERNÁNDEZ, Los remensas: evolución de un conflicto jurídico y social del campesinado catalán en la Edad Media, "Boletín de la Real Academia de la Historia", CLXXXVII/II (mayo-agosto 1990), pp. 217-297.

${ }^{3}$ La Pesta Negra i els origens, p. 29.

${ }^{4}$ FrEEDMAN, Els origens de la servitud pagesa, pp. 189, 186 i 193, respectivament.
} 
dempció."5 o J. Fernàndez Trabal: "En un nou context de fragilitat demogràfica i problemes de poblament (la segona meitat del segle XIV i el segle $\mathrm{XV}$ ), la remença s'utilitzà com a mitjà de retenir els pagesos als masos ..."

Malgrat tot, les recerques que tracten dels preus de les redempcions pagats abans i després de la Pesta Negra són relativament escasses ${ }^{7}$. J. Serra Vilaró va publicar les dades que oferien uns 75 exemples de les baronies de Pinós i Mataplana dels segles XIII, XIV i XV, i en concret 31 documents del període 1294-1348 i 11 documents de 1348 a 1411 . Amb aquesta mostra va arribar a la conclusió de que "arran de la Pesta Negra els preus de la remença no s'alteren gaire, però ben aviat s'hi nota el trasbalsament" ${ }^{\prime}$. $\mathrm{J}$. Vicens Vives opinà que a les predites baronies els preus dels enfranquiments van augmentar molt perquè arrel de la Pesta els senyors van practicar una política de "major restricció". De la mateixa opinió és Gaspar Feliu, que afirma que "el preu [de les redempcions de les suara esmentades baronies] va pujar enormement després de la pesta negra"10.

Posteriorment $\mathrm{P}$. Freedman ha confirmat aquesta tendència a l'alça amb les dades que oferien 50 cartes de redempció lliurades a la Pia Almoina de Girona - però de diversos dominis senyorials-, aquestes "mostren que el preu mitjà de les redempcions ... es doblà aproximadament en el període 1348-1400 [132,8 sous a 18 transaccions] en relació amb el període 1300-

\footnotetext{
${ }^{5}$ Antoni RIERA I MeLIS, El bisbat de Girona al primer terç del segle XV. Aproximació al context sòcio-econòmic de la sèrie sísmica olotina (1427-1428), a "Anuario de Estudios Medievales”, 22 (1992), p. 175.

'Josep Fernàndez Trabal, Una família catalana medieval. Els Bell-lloc de Girona $1267-$ 1533, Barcelona 1995, p. 420.

${ }^{7}$ L'any 1992 es publicà un estudi de Gaspar Feliu i Montfort centrat en el què podia suposar econòmicament la remença i els altres mals usos basant-se, sobretot, en l'estipulat pels Costums de Girona i en les obres dels comentaristes legals (El pes econòmic de la remença dels mals usos. "Anuario de Estudios Medievales". 22 (1992)).

${ }^{8}$ Joan SERRa VILARó, Baronies de Pinós i Mataplana. Investigació als seus arxius, II, Barcelona, 1947, p. 333.

${ }^{9}$ ViCEnS Vives, El Gran Sindicato Remensa, p. 10, nota 3

${ }^{10}$ FELIU, El pes econòmic de la remença, p. 156. A més a més, després de revisar les redempcions produïdes entre 1250 i 1450 dels pergamins conservats a l'Arxiu Fidel Fita d'Arenys de Mar arribà a la conclusió de que presenten la mateixa evolució a l'alça si bé amb preus més baixos que a les baronies de Pinós i Mataplana. Les redempcions i els preus obtinguts són els següents: $1303(20 \mathrm{~s}),. 1315(80 \mathrm{~s}),. 1336(20 \mathrm{~s}),. 1349(150 \mathrm{~s}),. 1350(25 \mathrm{~s}),. 1352(80$ s.), 1386 (140 s.), 1398 (220 s.), 1409 (22 s.), 1436 (33 s.), 1439 (150 s.) i 1447 (77 s.). Val a dir que no considerà els 2 sous i 8 diners pagats per les noies "verges".
} 
1348 [64,6 sous a 50 transaccions]" "I. També J. Fernàndez i Trabal, bo i referint-se també a terres gironines, afirma que "l'import de la redempció dels juvenis homo va experimentar una inflació constant" 12 .

En molts estudis sobre la pagesia medieval catalana o sobre algun altre aspecte de la Baixa Edat Mitjana, es fa referència als remences, a les redempcions i a la resta dels mals usos. Però, pel que fa a les redempcions, normalment només es recullen uns pocs exemples de diferents anys i de diferents senyorius, la qual cosa fa difícil considerar-los en el seu conjunt ${ }^{13}$. En cap cas, però, es discuteixen les tendències generals ja apuntades per $\mathrm{J}$. Vicens Vives o P. Freedman, en el sentit d'un enduriment de la condició pagesa a través de la remença, que es podia concretar en una restricció de les redempcions o en l'augment del seu preu.

En aquest estudi em proposo analitzar una mostra molt més àmplia, representativa i coherent de redempcions dels segles XIV i XV (que permeten posar en dubte les idees generalment admeses pels historiadors). Es tracta de més de cinc-centes redempcions referides a un sol domini senyorial i completades amb dades que n'expliquen els motius i altres circumstàncies que les acompanyen.

Aquesta anàlisi ha estat possible gràcies a una font prou coneguda - però mai utilitzada en aquest sentit- com són els Manuals de Comptes dels Pabordes de l'Almoina del $\mathrm{Pa}$ de la Seu de Girona ${ }^{14}$. Aquesta institu-

\footnotetext{
"FREEDMAN, Els orígens de la servitud pagesa, p. 189. 195)

'2FERnȦndez Trabal, Una família catalana medieval, p. 209 (quadre amb 3 casos a la p.

${ }_{13}^{13}$ Per exemple, E. de Hinojosa, Origen y vicisitudes de la pagesia de remensa i El régimen señorial; M. GOLOBARDES, Els remences dins el quadre de la pagesia; Coral CUADRADA, El Maresme Medieval: les jurisdiccions baronals de Mataró i Sant Vicenç/Vilassar (hàbitat, economia i societat, segles X-XIV), Mataró, 1988; Elisenda GràCIA I MONT, Estructura agrària de la Plana de Vic al segle XIV, Barcelona, 1989; Assumpta SERRA I Clota, La comunitat rural a la Catalunya Medieval: Collsacabra (ss. XIII-XVI), Vic, 1990; G. FelIU, El pes econòmic de la remença; FREEDMAN, Els orígens de la servitud pagesa; FERNÁNDEZ I TRABAL, Una família catalana medieval; Jordi de Bolòs, El mas, el pagès i el senyor. Paisatge i societar en una parròquia de la Garrotxa a l'edat mitjana, Barcelona, 1995; Mercè AvENTín I PUIG, La societat rural a Catalunya en temps feudals. Vallès oriental, segles XIII-XVI, Barcelona, 1996, entre d'altres.

${ }^{14}$ Aquests Manuals de Comptes de l'Almoina de Girona estan dipositats a l'Arxiu Històric de Girona. Christian Guilleré n'ha treballat certs aspectes, bàsicament a partir del bloc de les despeses, en els seus estudis sobre la Girona del segle XIV (Cf. Christian GuILLERÉ, Una institució benèfica enfront les adversitats de l'època: la Pia Almoina de Girona (1347-80), "Diner, poder i societat a la Girona del segle XIV", Girona, 1984, pp. 169-196 i Girona al segle XIV, II vols., Barcelona, 1993 i 1994). D'altres Pies Almoines també s'han conservat els seus llibres de comptes que han estat treballats en diversos estudis sobre alimentació, preus,
} 
ció, fundada l'any 1228 , posseïa, als segles XIV i XV, un domini molt dispers amb masos, terres $\mathrm{i}$ altres béns situats a la ciutat de Girona i a les actuals comarques del Gironès, La Selva, l'Alt i el Baix Empordà i el Pla de l'Estany.

Els Manuals de Comptes són llibres de comptabilitat on els pabordes anotaven tots els ingressos i totes les despeses de la Institució. Són llibres anuals que comencen l'l de juny d'un any i que acaben el 31 de maig de l'any següent, per aquest motiu els citem amb els anys coberts parcialment. El primer Manual conservat és de l'any 1331-1332 i l'últim de l'any 17761777. Es tracta, per tant, d'una excepcional font seriada de comptabilitat senyorial, si bé pel període que ens interessa, s'han conservat els Manuals dels anys: $1331-32,1332-33,1333-34,1334-35,1336-37,1337-38,1338-$ $39,1339-40,1340-41,1342-43,1343-44,1344-45,1345-46,1346-47,1347-$ $48,1348-49,1349-50,1350-51,1351-52,1352-53,1354-55,1358-59,1376-$ $77,1377-78,1378-79,1381-82,1385-88,1386-87,1389-90,1397-98,1398-$ 99, 1403-04, 1404-05, 1405-06, 1406-07, 1409-10, 1411-12, 1414-15, 1423$24,1429-30,1430-31,1431-32,1436-37,1439-40,1440-41,1444-45,1449-$ $50,1450-51,1451-52,1452-53,1457-58$, en el que es troba consignada l'última redempció i on, per tant, acabem la nostra anàlisi.

Tots aquests Manuals de Comptes tenen la mateixa estructura i cadascun està dividit en dos blocs: el dels ingressos i el de les despeses. Els ingressos, al seu torn, estan constituïts per dos apartats: en un d'ells el paborde corresponent hi consigna tots els censos que rep de les seves possessions i, en l'altre, tot el que s'anomenen "Foriscapis" en els Manuals. En aquest últim apartat és on es troben consignades totes les redempcions de persones pròpies, és a dir de remences, de l'Almoina. Els seus assentaments solen recollir el nom del redimit, la seva filiació, el seu mas d'origen i la seva parròquia. També hi figura el preu que paguen o la quantitat que ingressa l'Almoina per aquest concepte, així com la part que corresponia al

etc., també a partir del capitol de despeses. La comptabilitat de la Pia Almoina de Barcelona la va utilitzar María ECHÁNIZ (La alimentación de los pobres asistidos por la Pía Almoina de la Catedral de Barcelona según el libro de cuentas de 1283-1284", "Alimentació i societat a la Catalunya Medieval", CSIC, Institució Milà i Fontanals, annex 20 de l'“Anuario de Estudios Medievales", Barcelona 1988, pp. 173-261), també Pere ORTí [El forment a la Barcelona baixmedieval: preus, mesures i fiscalitat (1283-1345), "Anuario de Estudios Medievales", 22 (1992), pp. 377-423] i, sobretot, Tomás LóPEZ PIZCUETA en diversos articles i en la seva tesi doctoral. Els Ilibres de comptes de la Pia Almoina de Lleida els va utilitzar, per exemple, Prim BERTRAN [El menjador de l'Almoina de la Catedral de Lleida. Notes sobre l'alimentació dels pobres lleidatans al 1338,"Ilerda”, XL (1979), pp. 89-124]. 
paborde i als compradors de les rendes - quan aquestes estaven llogadesen cada cas. Sovint, a més a més, recullen els motius o altres circumstàncies que motivaren la redempció. A vegades, també hi figura el nom del notari i la data en què enregistrà l'enfranquiment en el manual notarial corresponent.

En els Manuals de Comptes hi són consignats tots els ingressos de l'any, per tant, podem afirmar que durant l'any corresponent al manual no es concediren més redempcions que les que hi consten ${ }^{15}$. D'aquesta manera, els Manuals de Comptes de l'Almoina de Girona permeten analitzar l'evolució cronològica de les redempcions tant pel que fa al seu nombre i als preus que es pagaren per elles, com pels motius que les generaren. També permeten analitzar - treball que reservem per a més endavant- la importància econòmica que les redempcions de les persones pròpies tenien per a l'Almoina i comparar-la amb la resta d'ingressos que, per altres conceptes, aquesta institució rebia dels seus dominis.

\section{EL NOMBRE DE REDEMPCIONS}

Des de l'any 1331-32 - any del primer Manual conservat - fins l'any 1457-58 - any en el que es consigna l'última redempció- es van redimir més de 540 persones pròpies de l'Almoina del $\mathrm{Pa}$ de la Seu de Girona. Aquest nombre s'ha obtingut gràcies al buidatge sistemàtic dels Manuals de Comptes dels seus Pabordes conservats.

Quan el paborde concedia una redempció, la consignava immediatament al Manual de Comptes d'aquell any, encara que el seu pagament no es realitzés en el moment del seu assentament. Així, coneixem una desena d'enfranquiments concedits en Manuals perduts perquè el seu pagament es

\footnotetext{
${ }^{15}$ Excepte, per exemple, el Manual de l'any 1334-1335 del que s'han perdut uns folis $\mathrm{i}$ dels dels anys 1333-1334 i 1339-1340 dels que només s’han conservat uns folis.
} 
va endarrerir i així apareix en l'apartat de deutes ${ }^{16}$ o com un pagament endarrerit ${ }^{17}$ en un Manual posterior.

Alguns assentaments dels Manuals de Comptes consignen l'enfranquiment de més d'una persona ${ }^{18} \mathrm{i}$, en un cas la quantitat de redimits resta indeterminada $^{19}$. Per tant, en aquest treball, s'han comptat les persones redimides, 540, i no els assentaments registrats.

\section{Les persones redimides}

Cal considerar, en primer lloc, quantes redempcions corresponen a homes i quantes a dones. Entre aquestes és important la distinció entre dones "verges" o "incorruptes", segons l'expressió utilitzada indistintament pels Manuals, i les que no ho eren perquè les primeres tenien el preu de la redempció taxat pel costum en 2 sous i 8 diners mentre que les altres pagaven un preu variable en cada cas, però sempre superior a aquesta xifra.

Però cal remarcar que, desconeixem en què es basava el paborde per distingir les noies "verges" de les altres. De fet, excloent les vídues i alguna pubilla - que pagava més perquè era hereva del mas-, el paborde no aclareix mai en els assentaments per què redimeix a alguna dona com a "corrupta" i no com a "verge". Encara que no podem saber com les distingia el paborde sabem que, de fet, ho feia. Així es desprèn, si més no, de l'assentament de l'enfranquiment de Perpinyana, filla de Jaume Mateu de Vilamorell, que paga 5 sous - gairebé el doble que una "verge"malgrat que s'hi escriu quod vis esset virgo que no sit $^{20}$. En aquest cas sembla que s'hi insinua la intenció del pare de la redimida de fer-la passar per "verge" per tal d'estalviar-se diners i pot ser també altres coses. Però,

\footnotetext{
${ }^{16}$ Per exemple, "P. Toron pagua XXXVIII sous que devia de la resamença de sa nora, segons apar en libra de XCVIII, en lo coern firmat a la fin del dit libra, en XXI fula del dit coern ...", a AHG, Hospici, Llibres de Comptes, 1406-07, fol. CXI. Aquest quadern s'ha perdut.

${ }^{17}$ Per exemple, "Item Bernardus. Venrelli, parrochie de Villa Asinorum debet qui restant ad solvendum pro redempcione persone sue, ut patet in libro Elemosine anni MCCCLVI, XL folio ...". A AHG, Hospici, Llibres de Comptes, 1358-59, fol. XXXIV v.

18 "Item dona hom a reembre G. Mir e sa muyler ..." a AHG, Hospici, Llibres de Comptes, 1349-50, fol. VIII [Celrà].

19“Mansus Gombau de Rivolutorum de Silva fuit datus ad libertatem pro servitute hominum et mulierum ...", el mateix Manual recull el nou establiment del mas, a AHG, Hospici, Llibres de Comptes, 1377-78, fol. LXXVII [Riudellots de la Selva].

${ }^{20} \mathrm{AHG}$, Hospici, Llibres de Comptes, 1334-35, fol. XXVII [Borrassà].
} 
cal preguntar-se com podia estar tan segur el paborde de que aquella que volia passar per "verge", en realitat no ho era?.

En aquest mateix sentit, el mateix any es redimí Guialmona, filla d'Arnau Candel de Viladasens, que pagà 2 sous i 8 diners com si fos "verge", però un temps després el paborde va escriure a sota del corresponent assentament: Hic fuit fraus quod posquam fuit corrupta fuit redempta. Aquest cas ens indica clarament que, per una part, el paborde es podia equivocar en decidir si una noia havia de redimir-se com a "verge" o no, o que se'l podia enganyar i, per l'altra, que en alguns casos el paborde seguia controlant les seves persones pròpies un cop ja redimides.

Els enfranquiments de noies "verges" que volguessin casar-se (així com els de les altres dones i els homes no hereus) eren automàtics, els Costums de Girona indiquen clarament que el senyor no s'hi podia $o_{0 p o s}{ }^{21}$; i fins i tot estipulen que si aquest no acceptava la redempció o era absent, només calia que el dia del casament de la noia es dipositessin els 2 sous i 8 diners esmentats sobre l'altar de la parròquia per tal que, d'aquesta manera, la noia en qüestió obtingués el propi enfranquiment ${ }^{22}$. En aquest sentit, cal remarcar que la quantitat de noies "verges" redimides no pot constituir un bon indicador d'una major o menor permissivitat de l'Almoina envers l'enfranquiment dels seus homes i dones propis.

A l'Almoina del Pa de la Seu de Girona, com arreu, les "verges" són, amb diferència, les que més es redimiren. En el nostre cas, estem parlant d'unes 331 noies enfranquides d'un total de més de 540 enfranquiments, és a dir, poc més d'un $61 \%$. Pel que fa a les redempcions d'homes, se'n redimiren més de 177 al llarg de tots els anys estudiats, és a dir, més d'un 32 '7\%. Les dones no "verges", que poden ser considerades "corruptes" o pubilles, són les menys representades. Només n'hem documentat 32 casos, és a dir, poc menys d'un $6 \%$ del total.

\footnotetext{
${ }^{21}$ Capítol 11, p. 64; també ho recull el capítol 37, entre d'altres dels Costums de Girona (Josep Maria PONS I GURI, Les col-leccions de costums de Girona, Barcelona, 1988).

${ }^{22}$ Josep Maria Pons GuRI. Document d'aplicació del dret senyorial, a "Recull d'estudis d'història jurídica catalana", III, Barcelona, 1989, pp. 193-196.
} 
QUADRE 1. LES REDEMPCIONS DE L'ALMOINA DE GIRONA 1331-1458

\begin{tabular}{|l|l|l|l|l|}
\hline ANYS & "VERGES" & HOMES & $\begin{array}{l}\text { DONES "NO } \\
\text { VERGES" }\end{array}$ \\
\hline $1331-32$ & 19 & 12 & & 31 \\
\hline $1332-33$ & 11 & 8 & 1 & 20 \\
\hline $1333-34$ & 1 & 1 & & 2 \\
\hline $1334-35$ & 11 & 8 & 1 & 20 \\
\hline $1337-38$ & 7 & 3 & & 10 \\
\hline $1338-39$ & 14 & 2 & & 16 \\
\hline $1339-40$ & 8 & 1 & & 9 \\
\hline $1340-41$ & 10 & 4 & & 14 \\
\hline $1342-43$ & 15 & 3 & & 18 \\
\hline $1343-44$ & 6 & 1 & & 7 \\
\hline $1344-45$ & 12 & 5 & & 17 \\
\hline $1345-46$ & 5 & 4 & 1 & 10 \\
\hline $1346-47$ & 11 & 1 & & 12 \\
\hline $1347-48$ & 20 & 7 & & 27 \\
\hline $1348-49$ & 22 & 17 & 7 & 46 \\
\hline $1349-50$ & 5 & 8 & 3 & 16 \\
\hline $1350-51$ & 3 & 4 & 2 & 9 \\
\hline $1351-52$ & 9 & 9 & 1 & 19 \\
\hline $1352-53$ & 1 & 2 & & 3 \\
\hline $1354-55$ & 1 & 2 & & 3 \\
\hline $\begin{array}{c}1358-59 \\
\text { deutes }\end{array}$ & 4 & 3 & & 7 \\
\hline $1376-77$ & 5 & & & \\
\hline $1377-78$ & 6 & 3 & 2 & 5 \\
\hline $1378-79$ & 7 & 3 & & 11 \\
\hline $1381-82$ & 8 & 2 & 1 & 10 \\
\hline $\begin{array}{r}1385-88 \\
\text { deutes }\end{array}$ & & 1 & & 11 \\
\hline $1386-87$ & 4 & 4 & 2 & 10 \\
\hline $1398-99$ & 9 & 1 & & 10 \\
\hline $1403-04$ & 3 & 2 & & 5 \\
\hline $1404-05$ & 13 & 4 & 1 & 18 \\
\hline $1405-06$ & 8 & 5 & 1 & 14 \\
\hline $1406-07$ & 6 & 6 & 1 & 13 \\
\hline $1409-10$ & 7 & 5 & & 12 \\
\hline $1411-12$ & 4 & 9 & & 13 \\
\hline $1414-15$ & 2 & 2 & & 4 \\
\hline $1423-24$ & 5 & 6 & 7 & 1 \\
\hline & & & & \\
\hline
\end{tabular}




\begin{tabular}{|l|l|l|l|l|}
\hline $1429-30$ & 7 & 1 & & 8 \\
\hline $1430-31$ & 3 & 1 & 1 & 5 \\
\hline $1431-32$ & 4 & & & 4 \\
\hline $1436-37$ & 10 & 4 & & 14 \\
\hline $1439-40$ & 5 & 1 & & 6 \\
\hline $1440-41$ & 7 & 2 & & 9 \\
\hline $1444-45$ & 5 & 4 & & 9 \\
\hline $1449-50$ & 2 & & & 2 \\
\hline $1450-51$ & 3 & 2 & & 5 \\
\hline $1451-52$ & 3 & 2 & & 5 \\
\hline $1452-53$ & & 1 & & 1 \\
\hline $1457-58$ & & 1 & & 1 \\
\hline \hline TOTAL & 331 & 177 & 32 & 540 \\
\hline
\end{tabular}

\section{Cronologia de les redempcions}

En el cas de l'Almoina de Girona i com ja ha estat dit, és ben cert que no s'han conservat tots els Manuals de Comptes dels segles XIV i XV; això no obstant, crec que ens n'han pervingut suficients com per intentar establir una cronologia més aproximada del conjunt de redempcions. Afortunadament, des de l'any del primer Manual -31- fins l'any 1353 s'han conservat pràcticament tots. La segona meitat del segle XIV compta amb un nombre inferior de Manuals, sobretot pel que fa als de les dècades dels anys 50 i 60, fins a finals dels 70, i des de llavors fins a finals de segle. En el segle XV, o més ben dit, fins l'any 1457-58, tenim menys buits documentals.

El primer Manual -1331-1332 - recull 31 redempcions, tant de "verges" com d'homes, però aquesta alta xifra d'enfranquiments no es repetirà fins el 1347-1348. Al llarg d'aquests quinze d'anys es consignen a cada Manual un mímin de 7 redempcions, amb una majoria aclaparadora de "verges" enfront de les altres categories: 150 (més d'un 70\%) d'un total de 213, 60 homes (més d'un 28\%) i únicament tres dones documentades (un 1’4\%). El Manual de l'any 1347-1348 (que acabava l'últim dia de maig 
de 1348) també registra un bon nombre de redempcions, molt majoritàriament de "verges" $(20 \text { de } 27)^{23}$.

El Manual corresponent a l'any 1348-1349, coetani a la Pesta a Girona $\mathrm{i}$ als seus voltants $\mathrm{s}^{24}$, és el que conté, amb diferència, un major nombre d'enfranquiments de persones pròpies de l'Almoina d'entre tots els considerats. Aquell any es redimiren 46 persones, 22 "verges", 17 homes i 7 dones, 4 d'elles vídues ${ }^{25}$. Aquest augment tan clar de redempcions concedides immediatament després de la Pesta Negra esdevé encara més significatiu si tenim en compte que es fa sobre la base d'una població molt més reduïda ${ }^{26}$. Per tant, enlloc de parlar -com ha estat fet-d'una minva i relativa escassetat de redempcions, crec que haurem de referir-nos, més aviat, a un clar increment.

Però els anys següents, 1349-50, 1350-51, 1351-52, 1352-53, 135455 , el nombre d'enfranquiments davallà a nivells més baixos que en el període precedent (vegeu quadre 1). El buit documental dels anys 1355 a 1376 ens impedeix poder apreciar quin va ser el signe de l'evolució posterior.

Un canvi significatiu que es produí durant els anys posteriors a la Pesta Negra és que la proporció de les noies "verges" entre els redimits va baixar mentre augmentava la d'homes i dones no "verges". En el període 1348-1355 el nombre de redempcions d'homes va ser idèntic al de dones "verges". Alhora el nombre de tretze dones no "verges" redimides durant els anys posteriors a la Pesta Negra contrasta amb els només tres casos que

\footnotetext{
${ }^{23} \mathrm{D}$ 'aquest any es conserven dos Manuals diferents amb informació també diferent. GUILLERÉ, Una institució benèfica enfront, p. 173, nota 17, creu que es tracta d'un esborrany que no fou completat a causa del canvi en els mètodes d'administració. Cal tenir present que 1347 és l'any en el qual el bisbe ordena la reforma dels estatuts de l'Almoina.

${ }^{24}$ Guilleré ha establert que la pesta va arribar a Girona i als seus voltants a mitjans del mes de maig de l'any 1348. GUILLERÉ, Girona al segle XIV, pp. 171-173.

${ }^{25}$ Curiosament, s'observa que tres germans s'enfranquiren a la vegada i una "verge" ho féu el dia abans que el seu germà, AHG, Hospici, Llibres de Comptes, 1348-49, fol. XIIII i XXIII v., respectivament.

${ }^{26}$ És impossible calcular la població morta a causa de la Pesta Negra en els dominis de l'Almoina de Girona per bé que indubtablement patiren les mortaldats. El paborde en Manuals posteriors es refereix a l'any 1348 com al tempore mortalitatis i, per exemple, el mas Noguer de Camós es va tornar a establir l'any 1366 perquè els seus propietaris moriren en la mortaldat del 1348 (ADG, Pia Almoina, Camós, pergamí núm. 213). En un futur immediat ens proposem estudiar el nombre de masos o de famílies que composaven el domini de l'Almoina, abans després de la Pesta, i, d'aquesta manera, podrem avaluar millor la importància d'aquest augment de redempcions. C. Guilleré proposa una disminució de la població d'entre un $15 \mathrm{i}$ un $20 \%$ a la ciutat de Girona (GUILLERÉ, Girona al segle XIV, vol. II, p. 179).
} 
es poden documentar enmig de les 213 redempcions consignades als Manuals de 1331 a 1348.

En el darrer terç del segle XIV i les primeres dècades del segle XV noves epidèmies sacsejaren la diòcesi de Girona que també es veié afectada pels terratrèmols dels anys 1427 i 1428 . Les conseqüències demogràfiques que se'n deriven són una nova davallada o estancament de la població ${ }^{27}$.

De 1376 a 1452 consten un total de 221 redempcions. Durant aquests anys també es mantingué una forta proporció d'homes i dones no "verges" entre els redimits (33\%), quantitat que es fa més patent en alguns anys concrets com són 1386-87, 1406-07, 1411-12, 1423-24, en els quals el nombre d'homes i dones no "verges" redimits superà al de dones "verges".

Aquest recorregut cronològic per les redempcions de persones pròpies de l'Almoina del $\mathrm{Pa}$ de la Seu de Girona s'interromp bruscament l'any 1457-58, quan es consigna la última redempció: un home que paga 10 florins el 5 de maig de 1457. Com hem dit, als següents Manuals conservats 1460-61, 1462-63, etc., ja no hi figuren més pagaments per enfranquiments.

Cal advertir que aquesta fita cronològica, de mitjans del segle $\mathrm{XV}$, també coincideix amb la desaparició dels documents de reconeixement de domini de l'Almoina a la parròquia de Camós ${ }^{28}$. Així, doncs, l'Almoina deixà de rebre reconeixements de senyoria $\mathrm{i}$ de concedir redempcions en aquesta data ${ }^{29}$. De la mateixa manera, a mitjans del segle XV, poc abans dels primers aixecaments remences, desapareixen en els apartats de foriscapis dels Manuals, els assentaments de cobrament relatius als altres mals usos.

Finalment, cal recordar que l'any 1455 el rei Alfons el Magnànim va abolir la prestació dels mals usos i les servituds rurals a canvi d'un

\footnotetext{
${ }^{27}$ GuILLERÉ, Girona al segle XIV, vol. II, pp. 189-213; P. VILAR, Catalumya dins l'Espanya Moderna, Barcelona, 1986, vol. I pp. 197-199: Ricardo GARCÍA CÁRCEL i María Vicenta MARTínEz Ruíz opinaren que "en 1427 la población era todavía prácticamente igual a la de 1378" i que "a mediados del siglo XV se produjo un gran descalabro demográfico" (Poblacion, jurisdicción y propiedad del obispado de Gerona (siglos XIV-XVII). Gerona, 1976. p. 41). A. RiERA parlant dels terratrèmols afirma que aquests "van recruar. ... a la Selva, la contracció economica. la davallada demogràfica i la inestabilitat social" (El bisbat de Girona al primer terç del segle XV, p. 196.).

${ }^{28}$ Rosa Lluch Bramon, Els remences de la Pia Almoina del Pa de la Seu de Girona. Fonts per al seu estudi i estudi preliminar. Memòria de Llicenciatura, Universitat de Barcelona 1995 inèdita.

${ }^{29}$ En aquest mateix sentit, la família Bell-lloc de Girona també deixà de rebre homentages i capbrevacions a partir del 1398 i des de llavors "exerciren molt esporàdicament el dret de la redempció (la darrera coneguda data de l'any 1437)". FERNÁNDEZ I TRABAL, Una familia catalana medieval, p. 352.
} 


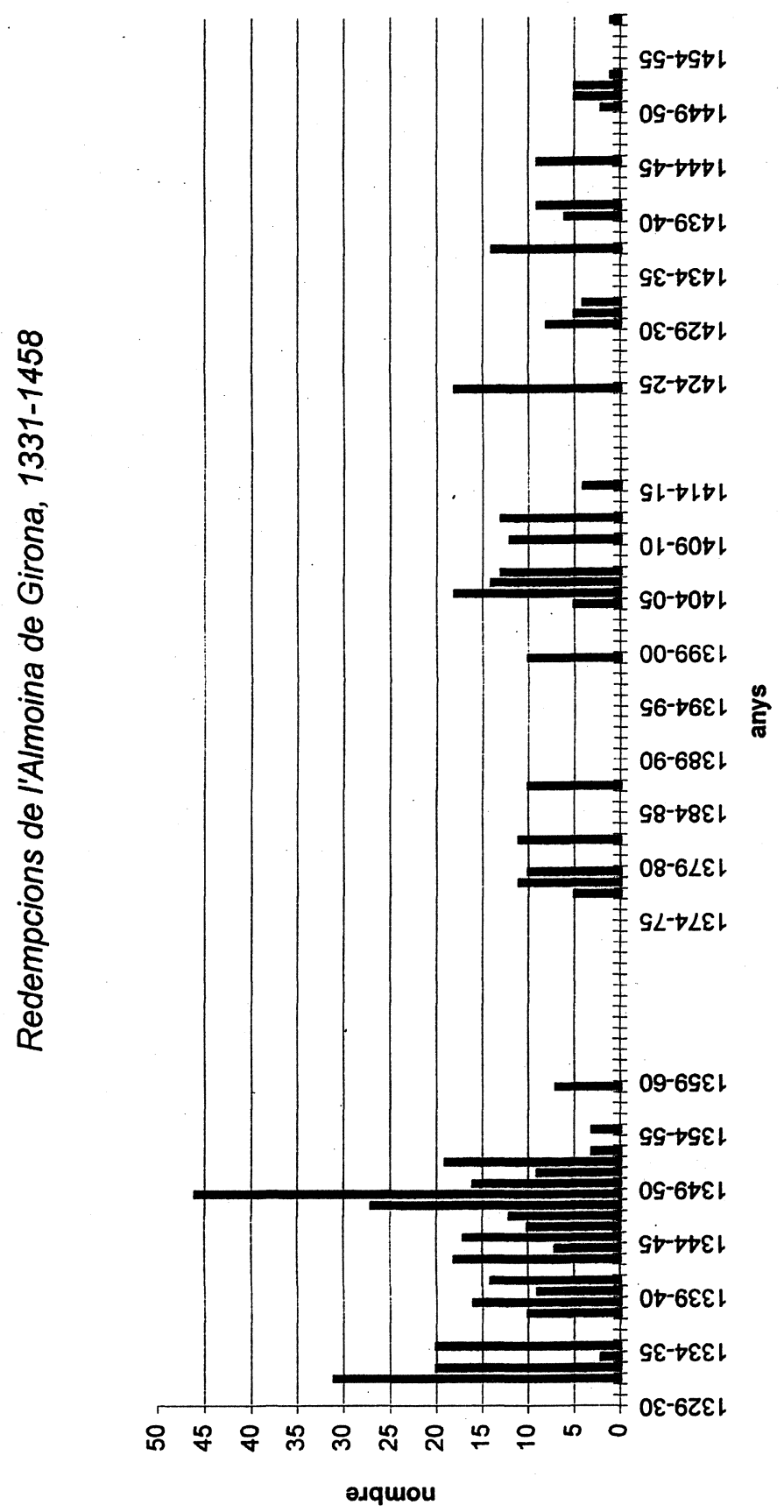


pagament de 100.000 florins, si bé l'any següent va suspendre aquesta sentència. Més endavant, però, el 9 de novembre de 1457, el mateix monarca, tornà a confirmar-la sentència $i$ especificà que es suspenien els següents mals usos: "redempció de persones, eixorquia, intestia, cugucia, àrsia, entrades i firmes d'espoli violentes" 30 .

\section{ELS PREUS DE LES REDEMPCIONS}

\section{Els preus als Costums de Girona}

El preu de les redempcions de les noies "verges" estava fixat en 2 sous i 8 diners, tal com es recull als Costums de Girona. Als assentaments dels Manuals de Comptes que recullen aquesta mena d'enfranquiments, el paborde a vegades i, sobretot, ja ben entrat el segle $\mathrm{XV}$, fa constar al costat del preu ut est moris episcopatus Gerunde, axi com és acustumat de paguar de infanta verge o anotacions similars ${ }^{31}$.

Pel que fa als preus de les dones no "verges" i als fills mascles, els Costums de Girona diuen que havien de pagar com a màxim l'equivalent a una tercera part dels seus béns ${ }^{32}$. Si el redimit no tenia béns o en tenia massa pocs, el preu es fixava en funció de les diverses condicions que reunia la persona i dels béns del mas que podria heretar ${ }^{33}$. Els Costums també estipulaven que el senyor no podia exigir la redempció de la vídua d'un home propi. Si ella acceptava l'enfranquiment, el preu de la seva llibertat tampoc no podia excedir a la tercera part dels seus béns. En cas de que fos

\footnotetext{
${ }^{30}$ VICENS VIVES, Historia de los remensas, pp. 56-59, vegeu també Jaume SOBREQUÉS i CAllicó, La crisi social agrària de la Baixa Edat Mitjana: els remences, "Estructura social i econòmica del camp català", Barcelona, 1983, p. 80.

${ }^{31} \mathrm{Cal}$ assenyalar, però, que fora de la diòcesi de Girona, el preu de les casadores no era el mateix arreu i, així, per exemple, Serra Vilaró parla de 10 sous, i fins i tot més, pagats per cada noia redimida a les baronies de Pinós i Mataplana; de fet, documenta un preu de 8 sous "que és el cas de donzella més a bon preu que he registrat" (cf. SERRA VIlaró, Baronies de Pinós i Mataplana, vol. II, p. 333.)

32“... A corruptis et filiis masculis habent sicut possunt cum eis convenire, dum tamen ultra tertiam partem non exiguant bonorum suorum ...", capitol 11, p. 64.

${ }^{33} \mathrm{Cf}$. capítols 11,37 , entre d'altres.
} 
la vídua la que es volgués redimir, el senyor en podria obtenir la quantitat que volgués ${ }^{34}$.

Sobre hereus i pubilles, els Costums són taxatius: uns i altres no es poden redimir ${ }^{35}$. Ara bé, si podien deixar un altre hereu al mas, llavors la redempció era viable i pagaven com qualsevol altre fill d'home propi.

Certament, seria interessant saber si es respectava o no el límit de la tercera part dels béns en fixar els preus de les redempcions, tal com es respectaven els 2 sous i 8 diners per a les noies "verges" estipulat pels Costums. Però els Manuals de Comptes no expliquen com es fixaven els preus enregistrats. Cal pensar, tanmateix, que eren un preus pactats entre el senyor i l'enfranquit i que podien contribuir en fixar-los diversos factors tals com l'edat, la capacitat de treball, la situació econòmica del redimit i del seu mas d'origen, la permanència al mas d'altres persones que el seguissin explotant, així com, tal i com assenyala Piskorski ${ }^{36}$, la possibilitat d'augmentar la població del mas d'origen, les opcions futures de l'enfranquit, etc.

En alguns casos, les famílies o els habitants d'un mas podien haver pactat ja el preu de totes les redempcions futures. Així s'observa, per exemple, en alguns documents d'homenatge o establiments ${ }^{37}$.

Si d'una banda, cal pensar que el senyor procurava obtenir el màxim de cada redempció, per l'altra l'home propi havia de poder pagar-la i això depenia de la seva disponibilitat econòmica o de la del seu mas d'origen. El pare, el germà o l'hereu eren, normalment els encarregats de pagar, només en vuit dels casos estudiats el paborde especifica que el propi enfranquit es fa càrrec de la pròpia redempció.

\footnotetext{
${ }^{34}$ Per exemple, capítol XXV de la compilació de Tomàs Mieres.

${ }^{35}$ Josep Maria PONS I GURI, Relació jurídica de la remença $i$ els mals usos a les terres gironines, a "Revista de Girona", 118 (1986), pp. 40-41.

${ }^{36}$ PISKORSKI, El problema de la significación, p. 40.

${ }^{37}$ Per exemple, el 17 de març de 1337, Guillem Devesa de Sant Dalmai, casat amb Ermessenda, prestà homenatge al paborde de l'Almoina per raó de la borda Creixell de Sant Dalmai, a condició de poder-se redimir ell per 30 sous i la seva esposa i els seus fills gratuîtament (ADG, Pia Almoina, Brunyola, pergamí núm. 773). HINOJOSA, El régimen señorial y la cuestión agraria, p. 214, on en transcriu un d'Amer de l'any 1280. També en presenta dos casos Bolòs, El mas, el pagès $i$ el senyor, p. 175, i un altre FERNÀNDEZ I TRABAL, Una família catalana medieval, p. 188.
} 
Per altra banda, és molt possible que, encara que es pogués pagar de cop el preu de la redempción ${ }^{38}$, aquest pagament comportés altres sacrificis econòmics que, de moment, se'ns escapen. Diem això, perquè cal pensar, que aquests pagaments no eren aïllats sinó que s'afegien a una sèrie d'altres condicions, així com a d'altres pagaments, tant ordinaris com extraordinaris. Creiem, doncs, que caldria contextualitzar els preus pagats en el conjunt d'obligacions econòmiques d'una persona o família en cada $\operatorname{cas}^{39}$.

\section{Els preus de les redempcions de l'Almoina de Girona}

Al llarg dels dos segles que considerem, hem trobat preus elevats i preus baixos, referits, uns i altres, tant a homes com a dones. Abans de la Pesta, per exemple, l'home que paga més, paga 300 sous (1334-35) i el que paga menys, en paga 6 i 10 diners (1342-43); després de la Pesta fins el 1400 , el preu individual més alt és de 400 sous $(1350-51)^{40}$ i el preu més baix de 5 (1348-49). Finalment, i durant la primera meitat del segle $\mathrm{XV}$, el més alt és de 385 sous (1429-30) i el més baix de 33 (1444-45).

Aquestes disparitats també es manifesten en els preus pagats per les dones, excloent-hi les "verges", tot i que generalment són més baixos que els pagats pels homes ${ }^{41}$. Abans de la Pesta, el preu més alt és de 40 sous (1345-46) i el més baix, de més de 3 sous (1332-33). Després de la Pesta, una vídua és qui paga el preu més alt, 260 sous (1377-78), i el més baix és de 5 sous (1348-49). Al segle XV, l'any 1405-06 es pagà el preu més baix, 25 sous, i l'any 1430-31 el més elevat, 165 sous.

\footnotetext{
${ }^{38}$ En menys d'una quarta part dels casos estudiats, i no precisament els de preus més elevats, el pagament es feu en diverses tandes o "entre diverses pagues e per diverses ayns". Però, en principi, tant és possible que la necessitat de més temps per pagar fóra deguda a què calia un cert temps per reunir tots els diners com a que no els interessés despendre-se'n de tots de cop i preferissin fer-ho escalonadament.

${ }^{39}$ En aquest sentit, són interessants les reflexions de W. Ch. Jordan quan en estudiar les redempcions forçoses dels pagesos de la zona del Sénonais al segle XIII conclou dient que si bé és cert que es pagaren els preus imposats, els pagesos trigaren temps a recuperar-se i que per això el mercat de la terra quedà estancat durant els anys immediatament següents (Cf. William Ch. JoRDAn, From Servitude to Freedom. Manumission in the Sénonais in the Thirteenth Century, Philadelphia, 1986).

${ }^{40}$ Tanmateix figuren 900 sous pagats per l'enfranquiment de tots els membres del mas Gombau de Riudellots de la Selva en el Manual de l'any 1377-78.

${ }^{41}$ Però, per exemple, en el Manual de l'any 1348-49 la redempció més elevada és la de Maria Carbonella d'Espinavessa que pagà 180 sous (AHG, Hospici, Llibres de Comptes, 134849 , fol. XXVIII).
} 
Les disparitats es manifesten fins i tot en les redempcions pagades per membres d'una mateixa família. Aquest és el cas de l'any 1331-32, en què es redimiren dos germans que pertanyien al mateix mas d'origen de Brunyola, Raimon i Estruc Seloni, el primer dels quals pagà 30 sous i el segon 40 , és a dir, una quantitat molt similar, però no igual ${ }^{42}$. Pocs anys més tard, el 1334-35, s'enfranquiren altres dos germans, Berenguer i Raimon Estrany, també de Brunyola, i el primer pagà 140 sous - un dels preus més alts d'abans de la Pesta Negra - i el segon menys de la meitat, és a dir, 60 sous $^{43}$. Aquesta diferència tan gran en els preus també s'observa en les redempcions de Ferrer Parayni i el seu fill Pere, ambdós de Riudellots de la Selva: mentre el pare hagué de pagar 140 sous, la llibertat del fill només en costava $25^{44}$. Altres casos reflecteixen la redempció de diversos germans al mateix temps, però, el preu pagat no sembla haver-se establert individualment sinó globalment ${ }^{45}$.

En un altre ordre de coses, algunes de les redempcions documentades semblen haver estat instigades pel paborde. Em refereixo, per exemple, a dos homes que són els únics redimits sense cap preu. Ambdós són propietaris de masos que no treballen ni volen treballar. En efecte, l'any 1406-07, l'Almoina estableix el mas Bofill de Fonolleres a Antoni, germà de Pere, fill de Bernat Joan de Canapost, que havia estat establert al mateix mas Bofill l'any 1403 per 90 lliures. L'assentament explica que en Pere no volia tenir el mas habitat ni treballat, que era vagabund i que deixava enderrocar les cases del mas, per la qual cosa el paborde es proposa d'establir Antoni en el seu lloc, a condició que prestés homenatge, fes contínua residència al mas i el tingués habitat i conreat. L'Antoni ho acceptà sempre i quan l'Almoina redimís al seu germà Pere sense cap preu ${ }^{46}$. L'altre cas ocorregué l'any 1436-37 a Brunyola, on en Berenguer Riera, àlies Devesa, home propi i propietari del mas Devesa era vaguabundus et quasi mentecamptus, tenia el mas tan abandonat que no quedava lapis super lapidem de tal manera que l'Almoina suos sensus nec agraria habere

${ }^{42}$ AHG, Hospici, Llibres de Comptes, 1331-32, fol. XXIII v.

${ }^{43}$ AHG, Hospici, Llibres de Comptes, 1334-35, fol. XVIII v.

${ }^{44}$ AHG, Hospici, Llibres de Comptes, 1378-79, fol. LXV.

${ }^{45}$ Per exemple, "Recepi de redempcione Berenguer Corney et Arnaldus Corney de Piru, fratres, CCXXX solidos ..." a AHG, Hospici, Llibres de Comptes, 1347-48, fol. XVI, entre d'altres.

${ }^{46}$ AHG, Hospici, Llibres de Comptes, 1406-07, fol. XLVII. 
minime poterat. És per aquest motiu que el paborde decidí enfranquir-lo sense cap preu i immediatament establí el mas a Pere Ferrera, àlies Sayes ${ }^{47}$.

El paborde es refereix a setze dels redimits com a vaguabundus, de poch poder o pobres. Aquest és el cas d'un matrimoni i un parell de germans - un dels quals és, a més a més, incensatus - els anys 1349-50 i 1351-52 respectivament; la resta pertany al segle XV i són un home l'any 1404-05, 4 l'any 1405-06, 2 el 1406-07, 1 el 1411-12, un altre l'any 141415 i, finalment, un home i un matrimoni l'any 1436-37. Entre ells només hi figuren dues dones que es redimeixen amb el seus marits. Cal assenyalar que aquest grup de redimits, excepte els dos casos ja ressenyats en el paràgraf anterior, es redimeixen pagant un preu no excessivament baix.

QUADRE 2. ELS PREUS DE LES REDEMPCIONS D'HOMES I DONES NO "VERGES" 48

\begin{tabular}{|c|c|}
\hline MANUAL & PREUS EN SOUS \\
\hline $1331-32$ & $+10,30,40,+40,50,55,60,60,+60,+60,+60,120$ \\
\hline $1332-33$ & +3 s. 1 d., $[20], 45,60,60,80,80,[80],[80]$ \\
\hline $1333-34$ & 50 \\
\hline $1334-35$ & $+5,40,50,60,+60,100,140,-300,300$ \\
\hline $1337-38$ & {$[50],[50], 100$} \\
\hline $1338-39$ & 10,60 \\
\hline $1339-40$ & 30 \\
\hline $1340-41$ & $28,50,60,75$ \\
\hline $1342-43$ & $6 s .10$ d., 10,50 \\
\hline $1343-44$ & 80 \\
\hline $1344-45$ & $30,60,60,70,80$ \\
\hline $1345-46$ & $40,50,70,80,100$ \\
\hline $1346-47$ & 60 \\
\hline$\overline{1347-48}$ & {$[15], 30,+64 \mathrm{~s} 3 \mathrm{~d}, 100,120,230(2$ germans $)$} \\
\hline $1348-49$ & $\begin{array}{l}\mathbf{5}, 5,11,[15],[25], 30,35,+45 \text { s. } 2 \text { d., } 48,+48, \mathbf{5 0},+52 \text { s. } 6 \text { d.(3 } \\
\text { germans), }+58 \text { s. } 6 \text { d., } 60,60,60,+60,[+62],[70], 80,[80], \mathbf{1 8 0}\end{array}$ \\
\hline $1349-50$ & $\begin{array}{c}+8 s .5 \text { d., } 21 \text { s. 11d., } 30,40,50,60 \text { (matrimoni), } 80 \text { (2 germans), } \\
120,240\end{array}$ \\
\hline $1350-51$ & $\mathbf{1 0}, 40,60,+80,-\mathbf{8 8 ,} 400$ \\
\hline
\end{tabular}

${ }^{47}$ AHG, Hospici, Llibres de Comptes, 1436-37, fol. LXXXVIII.

${ }^{48}$ Entre claudators la possible quantitat total pagada. En negreta els preus pagats per les dones no "verges". 


\begin{tabular}{|c|c|}
\hline $1351-52$ & $+10,30,40,45,50,50,+76,90$ (2 germans), 120 \\
\hline$\overline{1352-53}$ & 100,160 \\
\hline $1354-55$ & 60,90 \\
\hline $1358-59$ deutes & +22 s. $6 \mathrm{~d} .,+45,+112$ \\
\hline $1377-78$ & $150, \mathbf{1 6 5}, \mathbf{2 6 0}, 350,900$ \\
\hline $1378-79$ & $25,140,360$ \\
\hline $1381-82$ & $120,240,275$ \\
\hline $1386-87$ & $100,100,100,110,120,165$ \\
\hline $1385-88$ deutes & 220 \\
\hline $1398-99$ & 60 \\
\hline 1403-04 & 83 s. $6 \mathrm{~d}, 88$ \\
\hline $1404-05$ & $60,77,80,88,110$ \\
\hline $1405-06$ & $25,88,100,110,110,165$ \\
\hline $1406-07$ & res, $+38,66,77,88,99,110$ \\
\hline $1409-10$ & $44,66,66,110,220$ \\
\hline $1411-12$ & $60,77,77,110,110,143,154,154,209$ \\
\hline $1414-15$ & 154,242 \\
\hline $1423-24$ & $55,55,66,66,80,80,88,100,100,110,110,110,132$ \\
\hline $1429-30$ & 385 \\
\hline $1430-31$ & 165,165 \\
\hline $1436-37$ & res, $88,99,220$ \\
\hline $1439-40$ & 220 \\
\hline $1440-41$ & 88,400 \\
\hline $1444-45$ & 33,60 s. 6d., 66,110 \\
\hline $1450-51$ & 99,99 \\
\hline $1451-52$ & 44,110 \\
\hline $1452-53$ & 66 \\
\hline $1457-58$ & 110 \\
\hline
\end{tabular}

\section{L'evolució dels preus de les redempcions de l'Almoina de Girona}

Abans de comentar l'evolució dels preus de les redempcions d'homes propis de l'Almoina del $\mathrm{Pa}$ de la Seu de Girona, crec que val la pena fer unes reflexions. En primer lloc, cal dir que no sembla massa oportú fer comparacions entre realitats no ben bé iguals. És a dir, que no és del tot correcte comparar, per exemple, el preu pagat per un home qualsevol i de qui es desconeix la seva situació tant familiar com econòmica, amb el preu d'un altre home, si es té en compte que els preus eren fixats en cada cas i que, com hem dit en començar, aquests depenien d'una sèrie de factors molt diversos. Entre els quals no són pas dels menys importants les expectatives 
que s'oferien a l'home o dona propis enfranquits. Si aquestes eren millors el preu pagat podia ser més elevat i res no impedeix creure que, en efecte, les oportunitats ofertes a alguns remences després de 1348 fossin millors del que havien estat abans de la Pesta Negra.

En segon lloc, si fos cert que el preu sempre era proporcional al valor dels béns mobles del redimit, tal com establien els Costums de Girona, és a dir, si els Costums de Girona es complissin, tal com succeeix amb les "verges", creiem que no tindria sentit fer aquesta comparació i que, més aviat, el que caldria seria comparar el potencial econòmic de cada mas en concret. D'aquesta manera, la pujada o davallada dels preus de les redempcions estaria en relació directa amb l'enriquiment o empobriment del mas d'origen i del propi redimit i no pas amb altres circumstàncies, com podrien ser les marcades per la conjuntura del moment. En aquest sentit, caldria conèixer com evolucionen les economies pageses en aquests dos segles, perquè és molt possible que alguns pagesos que no s'arruïnaren milloressin la seva situació econòmica des de finals del segle XIV i durant el segle XV.

Per altra part, també hauríem de tenir present i conèixer l'evolució de la renda, de la moneda i dels preus, és a dir, caldria saber si els preus dels productes alimentaris, els salaris, etc. van augmentar o disminuir i quant per tal d'establir si efectivament els preus dels enfranquiments es van incrementar molt o poc. És a dir, creiem que no s'haurien d'analitzar els preus de les redempcions ailladament, sinó relacionar-los amb la resta de preus i de pagaments. Malgrat l'escassetat d'estudis prou seriosos pel període analitzat, els historiadors en general tendeixen a creure que després de 1348 hi hagué un procés inflacionista que potser es perllongà fins les primeres dècades del segle XV. Si aquestes dades es confirmessin caldria relativitzar un cop més el suposat augment del preu de les redempcions ${ }^{49}$.

Malgrat tot això en les redempcions concedides per l'Almoina de Girona no s'hi observa una clara tendència a l'alça just després de la Pesta Negra. Les mitjanes de preus dels anys coneguts d'abans de la Pesta no són espectacularment més baixes que les de després, ans al contrari. I això és especialment cert pel que fa a l'any següent, és a dir, el 1348-49 que, com

\footnotetext{
${ }^{49}$ Hamilton referint-se a Aragó i València parla d'augment de preus i salaris fins el 1380 , com a mínim; referint-se a Girona, Guilleré va concloure que “... no s'hi detecten variacions importants dels preus $\mathrm{i}$ dels salaris després de la pesta ..." i que hi ha una “... estabilització dels preus i dels salaris ... a partir del anys 1380-90 ..." (Girona al segle XIV, p. 328).
} 
ja hem assenyalat repetidament, és l'any en el que es produeixen més redempcions. El mateix succeeix l'any següent, és a dir, el 1349-50. En aquests dos anys, les mitjanes dels preus són fins i tot inferiors a les d'abans: 47 '5 i 59 sous, respectivament, enfront dels 79'8 de l'any 13471348 .

En conjunt, els preus pagats per les redempcions en el període 133148 no foren gaire diferents dels que es pagaren entre 1348 i 1359. En els catorze Manuals anteriors a la Pesta s'enregistren 63 redempcions d'homes i dones no "verges" que suposaren una mitjana de 66,2 sous per redempció. Mentre que en els sis Manuals posteriors, als que afegim tres casos de deutes del període 1348-59, és a dir 58 redempcions, pagaren una mitjana de $61^{\prime} 5$ sous per persona. Però, cal remarcar que el nombre d'homes i dones no "verges" redimits en els anys posteriors a la Pesta Negra foren de major mobilitat i, per tant, la quantitat anual que ingressava l'Almoina per aquest concepte era sensiblement més alta que en les dècades anteriors. Entre 1331 i 1348 el homes i dones no "verges" redimits pagaren una mitjana de 298 sous anuals. Per contra, entre 1348 i 1355 la mitjana fou de 564' 8 sous per any, degut, com s'ha dit a l'elevat nombre de redempcions concedides just després de la Pesta de 1348.

Certament els cinc Manuals del darrer quart del segle XIV enregistren pagaments força més elevats. Un total de 18 homes i dones no "verges van pagar una mitjana de 207 ' 7 sous per persona (que podria quedar reduilda a 170 sous si no es tenen en compte els 900 sous del mas Gombau de Riudellots de la Selva). Tot i que el nombre de redempcions havia disminuït en relació als anys immediatament posteriors a la Pesta del 1348, es pagà una mitjana anual de 748 sous per les redempcions d'homes i dones no "verges" (568 si no es compten els 900 sous esmentats), superior, per tant, a la de les dècades precedents i que confirmaria les dades recollides per J. Serra i Vilaró i P. Freedman amb mostres més reduïdes.

Finalment, durant la primera meitat del segle XV, el preu de les redempcions d'homes i dones no "verges" va davallar una mica, tot i situarse per damunt dels 100 sous de mitjana: 69 homes i dones propis havien de pagar un total de 7.437 sous entre 1403 i 1458. Però, tal com s'ha assenyalat, el nombre d'individus redimits es va reduir ràpidament a partir de 1425 i, per tant, si encara s'havien de pagar una mitjana de 601 sous anuals entre 1403 i 1424, aquesta xifra era només de 262 entre 1429 i 1458. És a dir, al nivell més baix enregistrat mai als Manuals de Comptes. 
En resum i en definitiva, amb la documentació estudiada de l'Almoina de Girona, podem apreciar que les mitjanes dels preus i els preus dels enfranquiments d'abans de la Pesta són lleugerament més alts que els posteriors i bastant inferiors als de finals del segle XIV i de la primera meitat del segle XV.

\section{CAUSES I MOTIUS DE LES REDEMPCIONS}

A partir de la segona meitat del segle XIV i, sobretot, des de finals d'aquest segle i durant la primera meitat del segle XV, els pabordes amplien la informació dels assentaments que recullen les redempcions dels Manuals de Comptes. Des de llavors, i excepcionalment abans, solen assenyalar molt breument el motiu pel qual l'Almoina concedeix la redempció, és a dir, ens donen informacions que d'alguna manera justifiquen o expliquen l'enfranquiment dels homes i dones propis de l'Almoina del Pa de la Seu de Girona.

Cal pensar que era una decisió presa per la persona pròpia - i també pel paborde - amb deteniment $\mathrm{i}$ analitzant totes les possibilitats que tenia. Això és especialment visible si tenim present que la redempció era del vincle amb el mas d'origen i que, per tant, l'home propi perdia la possibilitat d'ocupar-lo i conrear-lo; és a dir, que es quedava sense el seu mitjà de producció i de vida. En principi, tots els homes i dones que paguen la seva redempció abandonaven el seu mas d'origen o ja no hi vivien. Però, fora del domini de l'Almoina de Girona, en les parròquies veïnes es poden documentar excepcions. Per exemple, l'any 1350 els habitants d'un mas aconseguiren la reducció de serveis i servituds, inclosa la remença, amb un únic pagament anual de 60 sous $^{50}$.

En general, el senyor acceptava una redempció sempre i quan al mas d'origen hi quedava un hereu que el treballava. Tot sovint apareix aquesta seguretat, "... remanente herede dicto manso ..." als assentaments de redempcions dels Manuals de Comptes dels Pabordes de l'Almoina de Girona. Tot i això, veurem alguns pocs casos de redempcions d'homes $\mathrm{i}$ dones que deixaven el mas deshabitat, renunciaven als seus drets hereditaris i, d'aquesta manera, permetien al paborde establir-lo de nou.

\footnotetext{
${ }^{50}$ FERNÀndEZ I TRABAL, Una família catalana medieval, p. 188
} 
QUADRE 3. MOTIUS DE LES REDEMPCIONS

\begin{tabular}{|l|l|l|l|l|}
\hline ANYS & MATRIMONI & ALTRES & TOTAL MOTIUS & TOTAL REDIMITS \\
\hline $1331-32 / 1347-48$ & 3 & 1 & 4 & 213 \\
\hline $1348-49 / 1398-99$ & 38 & 19 & 57 & 161 \\
\hline $1403-04 / 1451-52$ & 98 & 27 & 125 & 166 \\
\hline TOTAL & 139 & 47 & 186 & 540 \\
\hline
\end{tabular}

\section{Matrimoni}

Són diverses les vies per les quals es podia sortir del mas d'origen. La més usual, com veurem, és la del matrimoni fora del propi mas, i això és especialment cert pel que fa a les noies "verges", la resta de dones i els homes no hereus. Sembla lògic que les anomenades noies "verges" abandonessin el seu mas d'origen per casar-se, perquè, la transmissió hereditària es feia preferentment a través dels homes o fills mascles i, per tant, el model de casament era virilocal (la dona es trasllada en casar-se a casa del seu espòs). Només les noies que no tenien germans es convertien en pubilles i llavors era el seu marit el qui venia a instal-lar-se a casa de la muller.

La majoria d'assentaments que consignen els motius que generaren les redempcions de les anomenades noies "verges" especifiquen que l'enfranquida s'ha de casar: ...fuit dada ad redimendum ... ... pro eo que duxerat in virum ..., ... per cant com ha sposat per marit ... o que ja s'ha casat, tal com consta com a mínim en vuit casos tot i pagar la tarifa habitual de les "verges" ( 2 sous i 8 diners) $)^{51}$. L'assentament dels Manuals de Comptes que recull aquestes redempcions, també sol consignar el nom de l'espòs, el del seu mas i el de la seva parròquia: “... Francisca, filia Petri de Ulmo, parrochie de Juygues, sponsa Bernardi Roderii de Palaciolo de Farguet, parrochie de Podialibus Rusticorum ..."52. Com que aquesta

\footnotetext{
${ }^{51} \mathrm{Cal}$ tenir present que una noia que s'hagués casat sense haver-se redimit abans podia ser castigada. Aquest és el cas d'una noia "verge" de Camós que, abans de casar-se, sí que s'havia redimit, però només del senyor que tenia dues terceres parts del dret sobre la seva persona i que, un cop casada, hagué de pagar 30 sous al senyor que en tenia la tercera i de qui no s'havia redimit (ADG, Pia Almoina, Camós, pergamí núm. 347[1335, agost, 26] i 346[1336, febrer, 23].

${ }^{52}$ AHG, Hospici, Llibres de Comptes, 1378-79, fol. XXVI.
} 
redempció només era requerida quan la noia es casava en un altre domini ${ }^{53}$, a vegades s'especifica que, pel casament, la persona redimida havia de canviar de senyor: "... pres per marit ... e avia a venir d'altra seyor ..." En d'altres casos - molts menys-, el paborde també deixa constància del senyoriu en el que entrarà la redimida: “... Maria ... fuit dada ad redimendum ... pro eo que duxerat in virum B. Mora de Crespiano, hominem proprium Domini Episcopi ..." 55 .

Des de 1370 fins a mitjans del segle XV, la gran majoria de noies "verges" enfranquides de les que en coneixem el motiu, es redimeixen per casar-se. Però, no només elles; sinó que aquest també és el motiu de les redempcions de la majoria de les altres dones (per exemple, 8 de les 11 redimides durant el segle XV) i d'una part considerable dels homes. Tal com s'observa al Quadre 3, el $75 \%$ del total de motius especificats en el pagament de la redempció es refereixen al matrimoni fora del mas d'origen.

Els Costums de Girona assenyalen que el senyor no es podia oposar a la redempció d'aquells que tinguessin intenció de casar-se i que no fossin l'hereu ni la pubilla del mas.

En un altre ordre de coses, els Costums de Girona establien que qui es casés amb un remença també se n'havia de fer. Si el cònjuge forani -el marit o bé la muller- no es feia propi del mateix senyor que el seu consort, aquell podia arribar a fer-los fora del mas. Abans, però, havia de requerir-li l'homenatge ${ }^{56}$. D'acord amb aquesta lògica si algú es casava fora del seu domini havia de redimir-se o eventualment fer que fos el seu cònjuge qui es traslladés de senyoria. Així s'observa en el següent cas: “Guillema, muyler d'en Guillem Merques de Crespian, és de la Almoyna per indivis ab la capela de Sent Jacme ça Garriga, el marit és de altra seyoria, sia citade que·s raema o faça vanir son marit de la seyoria" ${ }^{57}$. En aquest cas l'expulsió no

\footnotetext{
${ }^{53}$ Més endavant, veurem un cas en el que, excepcionalment i sorprenent, la persona redimida presta homenatge a l'Almoina per un altre dels seus masos poc després.

${ }^{54}$ AHG, Hospici, Llibres de Comptes, 1398-99, fol. LXXXIII.

${ }^{55}$ AHG, Hospici, Llibres de Comptes, 1377-78, fol. XXXI.

${ }^{56}$ En altres senyories s'han documentat casos en els quals un dels consorts era propi d'un senyor però l'altre no (cf. Serra VILARó, Baronies de Pinós $i$ Mataplana, vol. II, p. 331 CUADRADA, El Maresme Medieval: les jurisdiccions baronals, p. 518).

${ }^{57}$ AHG, Hospici, Llibres de Comptes, 1358-59, fol. LVIII.
} 
va ser necessària perquè el predit marit va acabar prestant homenatge a l'Almoina, si bé consta que ho féu amb un retard de vint anys ${ }^{58}$.

Els documents d'homenatge mostren a bastament que tant els homes com les dones es declaren remences pel fet d'haver-se casat amb un remença i haver-se instal-lat al seu mas. Així, si més no, ho confirmen les escriptures de reconeixement de domini conservades a l'arxiu de la mateixa Almoina de Girona ${ }^{59}$. Sovint es veu com, abans de prestar l'homenatge, presenten la carta de redempció rebuda del seu senyor anterior que demostra que són lliures, perquè sense haver-se redimit no es podien adscriure a cap altre senyor ${ }^{60}$.

Per acabar, creiem que tot el que acabem d'exposar ens permet afirmar que la majoria de redempcions - si més no les de l'Almoina de Girona- es produïren perquè els enfranquits es casaven fora dels seus dominis. En el mateix sentit, es constata que la major part d'aquests enfranquits, en casar-se, es veien obligats a redimir-se perquè la seva entrada en el mas del cònjuge implicava convertir-se en homes propis del senyor d'aquest.

\section{Trasllat a un altre mas sense matrimoni}

El paborde, en alguns assentaments de redempcions dels Manuals de l'Almoina de Girona, hi consigna com a motiu que el redimit ha d'entrar en un altre mas o en un altre senyoriu sense més explicació. Aquesta entrada pot ser provocada per diverses circumstàncies. En sis d'aquestes ocasions el paborde només anota que els redimits entren en un nou mas sense especificar-ne la via ${ }^{61}$, en una altra, un home es redimeix per tremudament

\footnotetext{
${ }^{58}$ AHG, Hospici, Llibres de Comptes, 1377-78, fol. CXIIII, l'assentament porta la data del 3 de gener de 1378 .

${ }^{59}$ Aquestes són les dades resultants de l'estudi dels documents d'homenatge que va rebre l'Almoina de la parròquia de Camós (LluCh BRAMON, Els remences de la Pia Almoina).

${ }^{60} A$ Així, per exemple, en un reconeixement de domini de l'1 d'abril de 1344 , s'escriu "et promito vobis tradere instrumentis redempcionis mee". ADG, Pia Almoina, Camós, pergamí núm. 186.

${ }^{61}$ Així s'observa en un home de Brunyola, en un pare i el seu fill de Riudellots de la Selva $i$ en tres altres homes de Camós, Vilavenut i Estanyol (AHG, Hospici, Llibres de Comptes, 1377-78, fol. LXIII; 1378-79, fol. LXV; 1381-82, fol. XXVII; 1386-87, fol. XXXI i fol. LXXIV v., respectivament). En tots ells s'hi consigna el mas al que es traslladen.
} 
de l'alberch ${ }^{62} \mathrm{i}$, finalment, hem trobat un cas en el que només es diu que l'enfranquit havia de canviar de senyoria ${ }^{63}$. Cal pensar que, tot i no dir-ho específicament, és possible que alguns d'aquests també es casessin i que potser aquesta va ser la via per la que entraren en un nou mas. Però, no està gens clar que fos així en vuit dels casos ressenyats.

Els homes propis podien traslladar-se a un altre mas perquè l'havien heretat o adquirit. Així es palesa en algunes de les redempcions de persones pròpies de l'Almoina, com és el cas de la de Guillem Mir i de la seva muller, de Celrà. En el Manual corresponent ${ }^{64}$, el paborde els descriu com a gent pobra que no avien res i afegeix que els ha pervengut un mas pel que s'havien de fer propis d'un altre senyor. De l'altra persona de qui ens consta que rebé un mas en coneixem el seu donador. Es tracta d'una noia de La Pera, redimida com a "verge", que s'enfranqueix perquè li és pervengut o la mara que li dóna el mas Vila de Flaçà ${ }^{65}$. D'acord amb el buidatge dels Manuals de Comptes, són només tres les redempcions provocades per la donació o l'herència d'un mas que pertanyia a un altre senyor. Però, cal pensar que la majoria de masos heretats no requeririen un canvi de senyoria perquè es farien dins el mateix senyoriu.

Finalment, només una de les redempcions és provocada per la compra i posterior entrada en un mas propi. Així consta que el 22 de febrer de 1423 Peregrina, vídua de Bernat Prat de Fonolleres, va ser redimida amb un preu de cent sous perquè havia comprat un nou mas que era el mas Bofill, també de Fonolleres ${ }^{66}$.

\footnotetext{
${ }^{62}$ Es tracta d'un nebot d'en Pere Serra de Serinyà que pagà 180 sous (AHG, Hospici, Llibres de Comptes, 1352-53, fol. XXXIII v.).

${ }^{63}$ Cas d'Antoni Pasqual de Palau Borrell però que s'estava a la parròquia d'Empúries i que pagà 66 sous (AHG, Hospici, Llibres de Comptes, 1423-24, fol. XLIII).

${ }^{64}$ AHG, Hospici, Llibres de Comptes, 1349-50, fol. VIII.

${ }^{65}$ AHG, Hospici, Llibres de Comptes, 1398-99, fol. LXVII.

${ }^{66} \mathrm{Cal}$ advertir que aquest cas és excepcional i únic entre els enfranquiments consignats en els Manuals de Comptes dels Pabordes. La redimida pagà alhora per la seva llibertat i 200 sous de lluïsme per la compra del mas que li costà 60 lliures. Poc després (el 29 de març de 1423) va prestar homenatge al paborde com a propietària del mas Bofill de Fonolleres que acabava de comprar i l'any següent, el seu marit, Fèlix Jordà, féu el mateix. És l'únic cas documentat en el qual una persona pròpia de l'Almoina es redimeix per poc després prestar homentage de nou a la mateixa Almoina però per un altre dels seus masos propis.
} 


\section{Viduitat i renúncia en favor de parents}

La documentació ens mostra quatre casos en els que la sortida del mas es produeix perquè els afectats han quedat vidus ${ }^{67}$. Tots tres havien entrat en el mas del que es redimeixen en casar-s'hi, però cadascun d'ells: ... habuit exire dictum mansum propter mortem eius uxor ... (o marit) segons el paborde. Fins i tot una de les dones ... habuit ... redire ac tornare ad mansum suum .... En tots quatre casos el preu de cada redempció el paguen els hereus del mas del que surten. En els assentaments dels Manuals que recullen aquestes quatre redempcions el paborde hi consigna que, pel fet d'haver-se quedat vidus, han d'abandonar el mas on vivien de casats, però cal pensar que altres persones també devien enviudar sense que abandonessin el mas del seu cònjuge. Els quatre casos esmentats recullen doncs una situació excepcional en la qual la viduïtat, segurament sense fills (si més no, aquests no consten i en un dels casos s'especifica que la morta mori axorcha), podia significar el retorn a la senyoria d'origen i la renúncia als drets de viduïtat sobre el mas del cònjuge difunt en favor dels parents d'aquest. Òbviament les vídues i vidus també podien redimir-se en motiu d'un casament en segones núpcies que impliqués traslladar-se a un altre mas tal com s'esdevé en el cas de la vídua de Ramon Blanch de Llampaies ${ }^{68}$.

En un altre ordre de coses, observem que quatre dels enfranquits, abans de redimir-se, renuncien als seus masos en favor d'algun parent. Així consta com Bernat Matella de Vilavenut "era hereu testamentari de son para [i], jac sia que no volgués usar de la dita heretat ne star en lo mas, per tant féu donació de dit mas ..." al seu germà Joan, que pagà el preu de l'enfranquiment i prestà homenatge a l'Almoina el mateix dia de la redempció ${ }^{69}$. Un altre cas és el d'en Guillem Caselles de La Pera, “... hom propi de la dita Almoyna e molt antich ...", que "... havia heretades en lo mas Casellas na Catherina, filla seva ..." ${ }^{70}$. En el mateix sentit, i com ja hem vist, s'ha d'interpretar la redempció de Pere Joan de Canapost ${ }^{71}$

\footnotetext{
${ }^{67}$ Es tracta d'una dona de Sant Gregori, d'un home d'Estanyol, d'un home de Vilavenut i d'una altra dona de Gaüses (AHG, Hospici, Llibres de Comptes, 1381-82, fol. XVIII v.; 1404-05, fol. XCVIII; 1423-24, fol. XXXII i fol. XL, respectivament).

${ }^{68}$ AHG, Hospici, Llibres de Comptes, 1377-78, fol. XXXIIII.

${ }^{69} \mathrm{AHG}$, Hospici, Llibres de Comptes, 1405-06, fol. XXXIIII.

${ }^{70}$ AHG, Hospici, Llibres de Comptes, 1406-07, fol. XLIIII v.

${ }^{71}$ AHG, Hospici, Llibres de Comptes, 1406-07, fol. XLVII.
} 
que renuncià al seu mas en favor del seu germà ${ }^{72}$. Finalment, Pere Gasuach, de Brunyola, va ser redimit per l'Almoina tot deixant en el seu mas a la seva germana a qui "... P. Gasuac die presenti hereditavit de omnibus bonis suis presentibus et futuris ...". Aquesta es comprometé a ferse càrrec de pagar el preu de la redempció, amb el consentiment del seu espòs $^{73}$.

El que no sabem, però, és on van anar a parar els esmentats enfranquits. En el cas d'en Guillem Caselles desconeixem, a més a més, per què va renunciar al mas en favor de la seva filla i si ell en va, o no, marxar.

\section{Renúncia en favor de l'Almoina i gent que no viu en el mas d'origen}

De la mateixa manera que alguns homes propis de l'Almoina es redimeixen després d'haver renunciat als seus masos en favor d'algun parent seu, també n'hi ha que renuncien als seus masos però en favor de l'Almoina. D'alguna manera aquestes redempcions podrien haver estat instigades o provocades pel paborde en funció dels interessos de la institució. Perquè cal pensar que a l'Almoina no l'interessava tenir cap dels seus masos desafocats i sense treballar pels que, per tant, non potebat abere sensus nec agraria. Sembla, doncs, que si l'hereu d'algun mas no el treballava però tenia algun parent a qui donar-lo el paborde acceptava que es fes així, però quan no hi havia cap parent, la persona pròpia, abans de redimir-se, renunciava a tots els drets que pogués tenir en el seu mas d'origen en favor de la mateixa Almoina.

Només en un cas, la redempció de Pere Castalà de Brunyola, el paborde només consigna que el mateix dia del seu enfranquiment renuncia lo mas Castalan de Brunyola a l'Almoyna ${ }^{74}$. Però, ara per ara, no sabem si aquest mas es va tornar a establir o no, ni si el redimit hi vivia o no.

Sis altres enfranquits que renunciaren al seu mas en favor de l'Almoina ja no hi vivien. De la majoria d'ells el paborde consigna que deixen el mas en molt mal estat. Cinc d'ells fa temps que no hi viuen, en

${ }^{72}$ El Manual de l'any 1423-24 registra que Peregrina Prat comprà l'esmentat mas Bofill per 60 lliures i que per aquest motiu es va redimir de la mateixa Almoina. Cal advertir, però, que en els Manuals conservats, no hem pogut localitzar quan Antoni Joan n'havia marxat.

${ }^{73}$ AHG, Hospici, Llibres de Comptes, 1439-40, fol. LXXXVI.

${ }^{74}$ AHG, Hospici, Llibres de Comptes, 1386-87, fol. LXX v. 
Joan Escampa viu a Mollet des de fa temps ${ }^{75}$, tot i que el paborde diu que és vaguabund e sens habitació, pagà 25 florins per la seva redempció ${ }^{76}$. Berenguer Riera, àlies Devesa, és vagabund segons el paborde ${ }^{77}$, el matrimoni del mas Bach Estrada de Camós viuen fora des de fa vuit anys ${ }^{78}$, i Antoni Sabater i la seva família, originaris de Serinyà, són commorans in parroquia de Pontonibus des de fa una vintena d'anys ${ }^{79}$.

Joan Escampa, abans de redimir-se, renuncia a tot dret que el pretenés haver en lo mas Ciprian e terres e possessions d'aquel del loch de Gahuses. Berenguer Riera és a més a més de vagabund titllat de quasi mentecamptus, potser per això del mas non remansit lapis super lapidem et dicta Elemosina suos sensus nec agraria habere minime poterat. L'Almoina l'estableix de nou immediatament. El mas Bach Estrada de Camós també està totus disruptus et incultus et parietes ... diraverunt totaliter ..., els seus propietaris són maleavosi et vagabundus i, abans de redimir-se, renuncien al mas i totes les seves pertinences. Segons el paborde paguen 25 florins per la seva redempcióo ${ }^{80}$. Finalment, el Manual de l'any 1440-41 consigna la redempció d'Antoni Sabater, la seva dona i els seus fills, considerato que dictus A. Sabater nec aliquis de sua familia non tam debat habitare in manso suo Sabater ... et Elemosina non potebat abere sensus nec agraria ..., [per tot això] fuit tractatum quod renunciaret dictus mansus et se redimat ... a canvi de 20 lliures. Aquest mas també és establert immediatament.

Així, doncs, sembla cert que existia la possibilitat de sortir del mas d'origen sense haver-se de redimir i que el fet d'establir-se en un nou lloc on treballar i viure no els eximia de continuar essent propis del mateix

\footnotetext{
${ }^{75}$ En l'assentament de la seva redempció presenten al seu pare com a "quondam de Molet". Al Manual de l'any 1381-82 hi consta que es redimí una seva germana "verge" i llavors el paborde escriví del seu pare, Pere Ciprià, "olim de Gahusis, nunc commorans in loco de Molleto, ubi se faci nominari Castillionis Escampa”. En els Manuals conservats no hi consta que el pare es redimís mai.

${ }^{76}$ AHG, Hospici, Llibres de Comptes, 1405-06, fol. XLII v.

${ }^{77}$ AHG, Hospici, Llibres de Comptes, 1436-37, fol. LXXXVIII [Brunyola].

${ }^{78}$ AHG, Hospici, Llibres de Comptes, 1436-37, fol. XXXXVIII.

${ }^{79} \mathrm{AHG}$, Hospici, Llibres de Comptes, 1440-41, fol. XXVIII.

${ }^{80} \mathrm{D}$ 'aquest cas hem pogut localitzar l'instrument notarial escrit el 6 de maig de 1438 . El notari va consignar que el paborde de l'Almoina del $\mathrm{Pa}$ de la Seu de Girona va definir absoldre de tot domini i servitud a Antoni Bach, ara ciutadà (?) de Girona i abans habitant propietari del mas Bach de Santa Maria de Camós, a la seva dona Margarida i tota la seva prole, nascuda i per néixer, i tots els seus béns per 11 lliures (AHG, Fons Notarial de Girona $6,173)$.
} 
senyor ${ }^{81}$. Fins i tot és possible que en algun cas la situació s'hagués perllongat durant molt de temps, tal com demostra el fet que els pares d'alguns redimits ja no visquessin al seu mas d'origen ${ }^{82}$.

Així, si més no, ho indiquen les redempcions que acabem de veure de la mateixa manera que les d'altres persones que tampoc viuen al seu mas d'origen. Fins i tot en algun cas aquest pot semblar el motiu dels seus enfranquiments. Són persones que des de fa temps viuen en altres viles o ciutats majoritàriament properes als seus llocs d'origen. D'alguns d'aquests homes redimits o d'alguns dels seus pares el paborde, en l'assentament dels Manuals, hi consigna a més a més del lloc on viuen ara, el seu ofici ${ }^{83}$.

De les més de 540 persones redimides per l'Almoina de Girona en el període treballat, més de 28 no vivien al seu mas d'origen. La majoria s'havien instal-lat en parròquies o viles properes al seu mas d'origen $i$ als dominis de la pròpia Almoina. Sis vivien a Banyoles i sis més a Monells però només un a Girona i dos a Barcelona. Només de disset d'ells el paborde en consigna el motiu de la seva redempció, però, com ja ha estat dit, d'alguns sembla que el motiu sigui precisament el fet de que viuen fora i de que ja tenen un ofici.

En un cas, l'any 1406, el paborde va requerir l'homenatge a en Narcís Sala, teixidor, stant a Barchinona, fill de Francesc Sala, traginer de Cassà. L'homenatge el va requerir davant del veguer de Barcelona, però s'hi oposava el síndic de la ciutat en nom de la ciutat i lo defenien axí com si fos ciutedan. Segons el paborde per esquivar plet e despeses fon concordat

\footnotetext{
${ }^{81}$ L'any 1404 Antoni Sabater de Serinyà havia prestat homenatge a l'Almoina per raó del mas Sabater (AHG, Hospici, Llibres de Comptes, 1403-04, fol. XXIII).

${ }^{82}$ Aquest és el cas, per exemple, del pare de Ferrera, redimida l'any 1382, "Petri de Falgueriis, alies Boscha de Monellis, qui origine traxit de Brunyola", i del pare de Brunissenda Falgueres (de Brunyola), que era carnisser a Monells on també es casa ella (AHG, Hospici, Llibres de Comptes, 1381-82, fol. LVIII i 1405-06, fol. LXXXIII v., respectivament).

${ }^{83}$ Així, per exemple, el pare dels dos germans Mascaró, originari de Camós, era carnisser a Banyoles; en Pere Picó de Vilavenut era sastre, també a Banyoles; en Narcís Sala era teixidor a Barcelona i el seu pare era traginer a Cassà de la Selva, i el pare de l'Antònia Carbonell era ferrer a la ciutat de Girona (AHG, Hospici, Llibres de Comptes, 1349-50, fol. XXII; 1404-05, fol. XXXIIII; 1406-07, fol. LIII v., i 1436-37, fol. XV, respectivament). En tot cas aquest fet no és exclusiu de la senyoria de l’Älmoina de Girona. A les baronies de Pinós i Mataplana es documenta, l'any 1344, la redempció d'un home magister lapidum o piquerius el germà del qual, també piquer, fou qui li pagà el preu de la seva llibertat. Segons Serra Vilaró “encara que piquers serien fills de pagesos de remença, els fills dels quals per lo pobladíssima que estava la terra en aquesta data, podrien abandonar la terra abans de redimir-se" Cf. SERRA VILARó, Baronies de Pinós, vol. II, p. 331.
} 
que fos donat a raemsa per 6 florins $^{84}$. Cal pensar que en Narcís Sala estava prou ben instal-lat a Barcelona com per a que el síndic el defensés. Aquest cas, per altra part, sembla demostrar que tot i que els seus homes propis visquessin fora del seu mas d'origen el paborde encara sabia on eren i els requeria l'homenatge.

De la informació aportada pel paborde en altres assentaments també es pot despendre que l'enfranquit no vivia al mas d'origen. Per exemple, el Manual de l'any 1414-15 recull la redempció de Francesc Caner, fill de Francesc Caner, difunt de Cassà, qui, segons el paborde, est vaguabundus et proposuit ire per mare, de totes maneres, pagà 14 florins ${ }^{85}$.

En qualsevol cas es tracta de persones que no havien entrat en un mas d'un altre senyor, cosa que sens dubte els hagués forçat a redimir-se per a poder fer homenatge al nou senyor. La seva adscripció majoritària al món dels oficis o la seva residència en una ciutat o vila semblen confirmar aquesta hipòtesi.

\section{Entrada a l'Església}

Finalment, set dels homes enfranquits per l'Almoina del $\mathrm{Pa}$ es redimiren per tal de convertir-se en clergues: l'any 1350 els germans Jaume i Joan Mascaró a qui el paborde defineix com a clergues coronats i que eren fills d'un carnisser de Banyoles, originari del mas Mascaró de Camós; l'any 1354-55 Berenguer Cots de Merlant perquè havia de rebre la tonsura; ja en el segle següent, el 1405 es redimí en Jaume Ros de Fallines al qual [el paborde] féu corona; l'any 1406 l'enfranquit fou en Joan Tassi, també de Camós, per tant com ha esperança que sia clergue e feu-li fer corona; l'any 1410 Pere Falgueres, fill d'un teixidor de Monells, qui de proximo debebat clericari; i, finalment, l'any 1423 es redimí en Nicolau Salvador de Fonolleres qui debet tonsurari ${ }^{86}$.

No sembla, doncs, que l'Almoina de Girona posés impediments majors perquè els seus homes propis entressin a l'Església, fins i tot quan es redimeixen els germans Mascaró el paborde els presenta ja com a clergues

${ }^{84}$ AHG, Hospici, Llibres de Comptes, 1406-07, fol. LIII v.

${ }^{85}$ AHG, Hospici, Llibres de Comptes, 1414-15, fol. LVI.

${ }^{86}$ AHG, Hospici, Llibres de Comptes, 1349-50, fol. XXII v., 1354-55, fol. IX, 1404-05, fol. XL, 1406-07, fol. XCVIII, 1409-10, fol. X, i 1423-24, fol. LIIII, respectivament. 
coronats i en dos casos més sembla que el mateix paborde els hi féu fer la corona $^{87}$. Cal tenir present que el tercer Concili de Tarragona, celebrat l'any 1370 , acordà que, sense consentiment del seu senyor, els pagesos de remença no poguessin rebre ordes sagrats ${ }^{88}$.

\section{CONCLUSIONS}

Els Manuals de Comptes dels Pabordes de l'Almoina del Pa de la Seu de Girona constitueixen una font excepcional per estudiar les redempcions de persones pròpies. El seu buidatge ha permès d'establir una mostra molt nombrosa d'enfranquiments (més de 540 casos) d'un sol domini i durant un llarg període de temps, des de l'any 1331 fins el 1458. D'aquesta manera hem establert la seva evolució cronològica i la dels preus que es pagaren per elles. Així mateix, la informació que contenen ens permetrà -en un futur- establir la importància econòmica que les redempcions tenien sobre el conjunt dels ingressos de l'Almoina.

Creiem haver demostrat que les redempcions concedides per l'Almoina de Girona no disminuïren després de la Pesta Negra, ans al contrari, augmentaren lleugerament durant els anys immediatament posteriors a l'epidèmia. Això és especialment cert si tenim en compte que la població havia disminuït. Cal afegir, a més a més, que augmenta significativament el nombre d'homes redimits enfront del de les dones i que, de fet, aquests anys són els únics en els que es redimeixen més homes que no pas noies "verges".

Per altra part, hem vist com els Manuals de Comptes deixen de consignar redempcions a mitjans del segle $\mathrm{XV}$, després d'uns anys amb molt poques. En aquest sentit cal subratllar que l'últim enfranquiment apareix al Manual de l'any 1457-1458, pocs anys abans del primer aixecament remença i, probablement, en relació amb la Sentència d'Alfons el Magnànim de 1455 que establia la suspensió de tots els mals usos.

\footnotetext{
${ }^{87} \mathrm{Al}$ Sénonais sembla que molts senyors concedien la llibertat als homes propis que volien entrar a l'Església, però si aquests en sortien els senyors els tornaven a considerar propis, cf. JORDAN, From Servitude to Freedom, pp. 82-83. En aquest sentit no sabem com actuava l'Almoina de Girona si es donava el cas.

${ }^{88} \mathrm{Citat}$ per HINOJOSA, Origen y vicisitudes de la pagesia de remensa, p. 20, nota 20 i PONS I GURI, Les col-leccions de costums, p. 164.
} 
Pel que fa als preus pagats per aquests enfranquiments, tampoc no sembla notar-se una diferència a l'alça entre el període immediatament posterior a l'esmentada Pesta i l'anterior, si no, més aviat, tot el contrari. Tanmateix, els preus de la primera meitat del segle XV sí que són més elevats, tot i que caldria comprovar si la resta de preus i de salaris també augmentaren i quant. Cal notar, en aquest punt que seria molt interessant poder saber amb seguretat si les pautes recollides als Costums de Girona sobre els preus es complien amb els homes i les dones no "verges" tal i com succeïa amb els 2 sous i 8 diners pagats sempre per les "verges". És a dir, si eren proporcionals als béns de la persona redimida i no superiors a una tercera part d'aquests. Si fos així, sembla clar que s'hauria d'estudiar l'evolució de les economies pageses - però també de les no pageses- i no els preus de les redempcions de les persones pròpies aïlladament o fora de context.

Tot el dit fins ara, i pel que fa a l'anàlisi concreta de l'Almoina del $\mathrm{Pa}$ de la Seu de Girona, pot portar-nos a concloure que el pretès enfortiment i enduriment del control senyorial després de la Pesta Negra no varià gaire en les concessions de redempcions; i això tant pel que fa al seu nombre com al seu preu. L'únic aspecte que varià, i molt, fou que després de la Pesta hi hagué un clar i fort increment de redempcions d'homes, potser a causa d'un major nombre de masos deshabitats i, per tant, de més oportunitats per sortir del mas d'origen i establir-se en un altre.

Hem observat que un nombre significatiu dels redimits ja no vivien en el seu mas d'origen, que era el que els exigia la redempció. Aquesta circumstància, per tant, sembla indicar-nos que podia existir la possibilitat de sortir del mas d'origen sense haver-se redimit i establir-se en alguna altra parròquia o vila on, fins i tot, es podia arribar a tenir un ofici. Però queda clar que això no els eximia d'haver-se de redimir més endavant.

La major part dels casos documentats on consta el motiu de la redempció palesen que la gran majoria de redimits ho feren per casar-se. Pràcticament tots ells, en fer-ho, entrarien en un altre mas remença que els obligaria a fer-se propis d'un altre senyor i, així, esdevenir de nou, remences. El mateix hem observat amb altres redimits que es redimien per altres motius $i$, en conseqüència, creiem que aquestes redempcions, en la gran majoria de casos, suposarien més aviat un canvi de senyoria i no el pas cap a la definitiva llibertat. 


\section{RÉSUMÉ}

Le but de cette recherche est de tenter d'approcher la situation de la paysannerie de remença (serf de la glèbe) dans le diocèse de Girona pendant le Bas Moyen Age.

L'objectif premier en est l'étude des rançons: c'est-à-dire le rachat de la liberté personnelle des remences de l'almoina del pa (l'aumône du pain) du siège épiscopal dans la période comprise entre 1331 et 1458. Cette rançon, si caractéristique en Catalogne, a fini par donner son nom aux paysans qui y étaient soumis.

Dans le cadre de ce travail plus de cinq cents rançons ont était étudiées. Elles correspondent toutes au même domaine territorial et étaient consignées dans les manuels de comptes des Pabordes de l'Almoina de Girona. Cette source documentaire était déjà connue mais jamais elle n'avait été utilisée dans ce sens.

Le suivi chronologique du prix et du nombre de rançons est l'un des points qui a guidé cette recherche, mais celle-ci s'attache également à l'analyse des divers motifs qui ont été á la base de leur création.

\section{SUMMARY}

This paper deals with the situation of the servile peasantry of the diocese in Girona during the Late Middle Ages. Its purpose is to the study the redemptions -that is to say, buying one's own freedom- of the remences from the Almoina del Pa de la Seu de Girona from 1331 until 1458. Such a usual redemption is what gives the name of remences to the peasants who were bound to the servile link in Catalonia.

More than five hundred redemptions that were studied belong to the same domain and are included within the Account Books of the Charity Institution. Such well-known source has never been used in this sense up to now. It not only allows to know the number of manumited people but also the prices that were paid for their freedom and the reasons that caused their redemption.

Thus, this paper analyses the chronological evolution of the redemptions, in both cases: on one hand, their quantity and the prices that were paid for them and, on the other hand the reasons that provoked them. 